\title{
¿El fin de la administración pública?
}

Guerrero, Omar (2003), Gerencia pública eN LA GLOBALIZACión, Universidad Autónoma del Estado de México, Grupo editorial Miguel Ángel Porrúa, MéXico, 376 PP., ISBN: 970-701-346-X

El término globalización es uno de los referentes más utilizados para señalar el origen de muchos de los trastornos que experimentan en la actualidad los Estados y sus sociedades. Bajo esta denominación se ha tratado de explicar la agudización de problemas ancestrales, como la polarización en la distribución de la riqueza y la pérdida de identidad de grupos y comunidades. La mayor parte de los análisis referentes a este concepto se han centrado en aspectos meramente económicos, dejando de lado las implicaciones que ha tenido en la organización administrativa de los países, aspecto primordial para entender las transformaciones recientes de los gobiernos en la atención de los reclamos cada vez más complejos y numerosos de sus sociedades.

En este contexto es de gran utilidad la aparición de la obra Gerencia pública en la globalización, de Omar Guerrero Orozco, ya que en ella se analiza el impacto que ha tenido la globalización económica en las administraciones públicas nacionales a través de su postulado new public management, ${ }^{1}$ el cual ha intentado transformar -de manera radical- el papel que el Estado ha desempeñado históricamente como garante del desarrollo social y económico de las naciones, lo cual, en su opinión, representa el más grande desafío que ha enfrentado la administración pública desde que Frederick Taylor y Henri Fayol pregonaron la incorporación de técnicas gerenciales en los procesos de gobierno.

La posición del autor sobre el tema es de abierta crítica hacia el neogerencialismo que ha instaurado la idea de un Estado reducido enfocado a resultados y cuyos ejes rectores se basan en prácticas que habían sido consideradas exclusivas del mercado y la administración privada. A lo largo del texto se realiza una defensa de la administración pública, argumentando que su naturaleza y su función no pueden reducirse ni supeditarse a los postulados

\footnotetext{
${ }^{1}$ Este término ha sido traducido como: 'neomanejo público', 'nuevo manejo público', 'nueva gerencia pública', entre otros. Omar Guerrero prefiere el segundo, aunque en el libro hay un uso indiferenciado de estos términos.
} 
de la teoría neoclásica de la economía, por su separación de la política y la noción de lo público.

El libro se centra en el estudio de dos fenómenos: la gerencia y la globalización en el contexto de multigobiernos con mayores niveles de relación, y con un incremento de insumos internos y externos que influencian sus decisiones. Para ello, los nueve capítulos que lo componen se pueden dividir en tres apartados temáticos. El primero introduce al problema y aborda los orígenes de la globalización. El segundo analiza la emergencia de este fenómeno en el terreno económico y comercial, así como su inferencia en los procesos de reforma administrativa guiados por el nuevo manejo público. Por último, el autor establece perspectivas alternas frente al modelo globalizador imperante.

Guerrero identifica a la 'modernización' como el origen reciente de la globalización. Dicho proceso consistió en acompasar a los países subdesarrollados al ritmo del progreso de sus contrapartes desarrolladas, principalmente mediante la formación de institutos internacionales de administración pública durante la década de 1960. La idea consistió en brindar asistencia técnica a los países recién independizados que enfrentaban la carencia de funcionarios locales especializados. Para ello, la Organización de las Naciones Unidas llevó a cabo diversas reuniones internacionales y estableció programas conjuntos entre 1971 y 1985 con el fin de fomentar la racionalización administrativa y la preparación de los empleados públicos. Sin embargo, los países desarrollados no mostraron un interés real en que sus ex colonias lograran dicha modernización administrativa al no introducir los principios básicos de la administración pública, limitándose a transformar a los funcionarios nativos en meros ejecutores de las políticas por ellos establecidas.

La aplicación de 'fórmulas únicas', sin considerar las peculiaridades de los países asistidos, impidió que las prácticas enraizaran en sus instituciones y cultura, sobre todo en África y Latinoamérica, los cuales agudizaron su precaria situación al enfrentar el incremento de los índices de desempleo e inflación, así como graves niveles de inestabilidad política.

Por su parte, en los países desarrollados el Estado también enfrentó serias críticas sobre su desempeño a finales de la década de 1970, debido a la carencia de recursos financieros y el cuestionable nivel de eficiencia en procesos y sistemas administrativos, lo cual condujo a la puesta en marcha de estrategias que tuvieron como objeto su transformación. El modelo aplicado respondió - 
en gran medida- a la dinámica propia del empresariado, siendo la privatización uno de sus ejes rectores.

De acuerdo con Guerrero, el nuevo ideario provino del Informe Berg, realizado en 1980 por Elliot Berg para el Banco Mundial, cuyo diagnóstico exaltaba la ineficiencia de las empresas públicas, la impericia del funcionariado y la operación de instituciones sin criterios de rentabilidad. Las medidas a aplicar, entonces, serían la reorganización, la reducción y la descentralización en primera instancia-para obtener utilidades que posteriormente serían destinadas al beneficio social. Esta cultura, basada en el utilitarismo y la racionalización, conllevó a la orientación final del mercado como guía de lo que debía ser la administración pública.

La emergencia de la globalización y la reforma administrativa basada en el nuevo manejo público, abordada en los capítulos cuarto, quinto y sexto de la obra, postuló la promoción de los mercados, la competencia, el patrocinio empresarial y la orientación hacia el cliente, alterando de manera sustantiva la misión, fines, organización y funcionamiento del Estado. El pensamiento económico neoclásico, sustento teórico del modelo globalizador, estableció que éste debía desvincularse de la administración pública, la cual sería sustituida por la 'nueva gerencia pública' que considera a la población ya no como ciudadanos, sino como clientes o consumidores, así como establece que el gobierno debe adecuarse a la empresa privada, es decir erradicar la omnipresencia de la administración pública en la vida y actividades de los particulares.

Omar Guerrero destaca que la justificación para aplicar estas medidas intentó ser contundente: con base en encuestas realizadas por la Organización para la Cooperación y el Desarrollo Económico (OCDE), se estableció que el Estado era inviable por la lentitud que mostraba hacia los problemas, por su escasa apertura al cliente y por la ineficiencia de sus funcionarios. Sin embargo, el autor cuestiona estos resultados y su influencia en los países más prominentes de la OCDE, por ejemplo, Francia, Inglaterra y Estados Unidos, donde aún no se habían suprimido "el Estado de derecho, la división de poderes, o bien, no han cesado a jueces, ni erradicado la carrera administrativa o despedido parlamentarios".

La solución a estos males radicó en la aplicación del modelo estándar neogerencial, por medio del cual se intentan mimetizar ciertas prácticas de la empresa privada en la administración pú- 
blica, así como transformar la conducta y actitudes de los servidores públicos, prestando una mayor atención a los resultados en cuanto eficiencia, eficacia y calidad en el servicio, y reemplazando estructuras jerárquicas y centralizadas por una gerencia pública descentralizada.

El nuevo estilo administrativo se personalizó en la gestión pública (public management), cuyos principales signos distintivos han sido: a) la prestación de servicios al cliente, b) el establecimiento de mercados en el seno de los procesos gubernamentales, c) el desarrollo de la competencia mercantil entre dependencias, d) la orientación empresarial de tipo privada dentro del Estado, y e) la separación tajante entre política y administración.

Los autores en los que se han basado estas propuestas han sido Thomas Peters y Robert Waterman (In search of excellence, 1982) y, recientemente, David Osborne y Ted Gaebler (Reinventing government: how the entrepreneurial spirit is transforming the public sector, 1992), aunque debe destacarse que, como lo afirma el autor, las fuentes primarias de la aplicación de la ideología de mercado en el sector público son más antiguas: la escuela austriaca de economía, representada por Ludwig Von Mises y Friedrich Hayek, quienes establecieron que para convertir al Estado en una organización eficiente es necesario que introduzca prácticas propias del sector empresarial, por ejemplo, el cálculo de pérdidas y ganancias, así como la competencia y la descentralización. ${ }^{2}$

Es un hecho que el modelo fue aplicado con decisión en diversos países, sin embargo, Guerrero destaca el caso británico por su naturaleza y alcance, lo cual le valió haber sido calificada como la "personificación misma" del nuevo manejo público. El ideario reformista británico contempló la utilización de métodos, conceptos, modelos y valores de los negocios privados para transformar su administración pública. Sin embargo, debe notarse que la aplicación del modelo gerencial, acompañado de otras políticas propias de la globalización económica, ha tenido saldos negativos para las sociedades. La segunda parte del libro da cuenta de lo anterior, argumentando que el debilitamiento de la figura estatal y de la administración pública han afectado directamente la provisión de los servicios sociales, ocasionando un aumento acelerado de la pobreza, la pérdida de la base económica de los trabajadores capacitados, la descapitalización de los sistemas de educación y de salud, entre otros aspectos, lo cual ha llevado a la

${ }^{2}$ Véanse Von Mises (1976: 1-81) y Hayek (2000: 62-87). 
conclusión de que el Estado, tal y como se ha conocido tradicionalmente, posee un "carácter capital en la promoción del desarrollo social" porque sólo él puede "diseñar e implementar policies sociales en gran escala y asegurar su coordinación eficaz".

Finalmente, el tercer apartado de la obra analiza diversas perspectivas frente al modelo globalizador. Partiendo de la premisa de que el Estado burocrático es aún relevante en sectores donde el gobierno necesita hacer algo más que optar entre bienes y servicios, cita el caso alemán para demostrar que existen alternativas frente a la opinión extendida de las irrefutables bondades del nuevo manejo público, ya que en ese país, desde la década de 1990, el gerencialismo no ha sido visible, ni los funcionarios han sido 'golpeados' por los políticos o por el público. En Alemania, la burocracia weberiana se ha mantenido estable en su sentido legal-racional, es decir ha mantenido criterios objetivos, jerarquía dentro y entre organismos, jurisdicciones especiales y una clara distinción entre medios de administración públicos y privados.

Asimismo, el autor llama la atención sobre lo que denomina "la experiencia administrativa más trascendente emprendida por la humanidad del siglo xxI": la Unión Europea, en la cual la hechura de políticas se ha realizado -aún con limitaciones- por medio de negociaciones entre gobiernos políticamente autónomos. Este hecho reconoce la importancia del factor político en el ideario y desempeño de la administración pública.

Luego de una serie de análisis sobre el nuevo manejo público y su impacto en las administraciones públicas, Guerrero afirma que el debate central es una edición renovada de los antiguos problemas suscitados en las fronteras de la administración de negocios y la administración pública ("vino viejo embotellado como nuevo"), por lo cual el carácter de innovación que se le ha adjudicado es cuestionable.

Omar Guerrero responde a la duda que guía su investigación afirmando que el fin de la administración pública no está por llegar ni en el corto ni en el mediano plazo, principalmente, por el desprecio que el nuevo manejo público hace de las relaciones entre la administración pública y el contexto del ejercicio del poder, así como la debilidad teórica del modelo gerencial que le impide constituirse en un nuevo paradigma o en una opción real de transformación de la administración pública.

La lectura de esta obra también aporta reflexiones útiles sobre el ejercicio de gobierno, por ejemplo, la ilusión de creer que existan 'fórmulas únicas' exitosas que puedan aplicarse de forma ex- 
traterritorial, así como la necesidad de considerar a la administración pública de cada país con referencia a sus estructuras, instituciones y procedimientos. Las experiencias acumuladas desde los intentos de 'modernización' hasta la fecha demuestran que se debe transitar de la adaptación sin concesiones a la innovación creativa en materia de reformas administrativas.

Por otro lado, a pesar de que la obra ofrece argumentos para cuestionar la utilidad del modelo global de administración basado en el mercado, también es conveniente resaltar algunas de las aportaciones que han sido útiles a las administraciones tradicionales, entre ellas, el establecimiento de organismos y procedimientos administrativos modernos y apolíticos, la inclusión de tecnologías de automatización en oficinas, registros eficientes de manejo presupuestario y financiero, así como estrategias para la evaluación del desempeño, planificación estratégica, trasparencia, rendición de cuentas y descentralización en la toma de decisiones.

Sin duda, esta obra constituirá una valiosa fuente de argumentos para estudiosos del tema, funcionarios públicos y público interesado, con el fin de analizar las reformas emprendidas en los años recientes por los gobiernos de los países tanto desarrollados como subdesarrollados, cuyos ejes han sido la reducción de la figura estatal y la transición de la administración pública hacia el manejo gerencial a través de la adopción de prácticas propias del sector privado.

Los lectores de Gerencia pública en la globalización encontrarán una interesante defensa de la administración pública basada en la investigación y el análisis del neogerencialismo para, de esta forma, obtener sus propias conclusiones respecto del papel que debe seguir el aparato público estatal en el futuro con miras a realizar de manera eficiente y puntual su función primaria: materializar los intereses de la población en su vida cotidiana.

\section{Bibliografía}

Von Mises, Ludwig (1976), Burocracia, Unión Editorial, Madrid.

Hayek, Friedrich (2000), Camino de Servidumbre, Alianza Editorial, Madrid.

Juan Manuel Barrera Grageda

CRIM-UNAM

jmbarrera@correo.unam.mx 